\title{
Emerging therapeutic potential of transdermal clonidine: a prospective as an adaptogen
}

\section{Gregory Goldenberg}

Department of Medicine, New York Methodist Hospital, Brooklyn, NY, USA

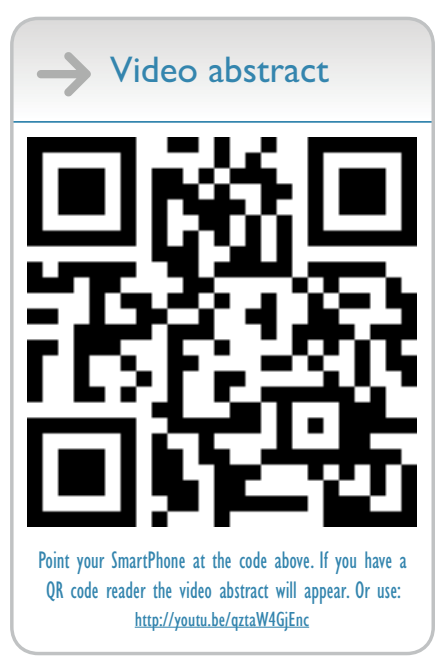

Correspondence: Gregory Goldenberg Department of Medicine, New York Methodist Hospital, 6th floor, 2792 Ocean Avenue, Brooklyn, NY II229, USA

Email gregonline_2000@yahoo.com
This article was published in the following Dove Press journal:

Research and Reports in Transdermal Drug Delivery

23 November 2015

Number of times this article has been viewed

\begin{abstract}
Clonidine (CLO) has become popular in fields other than treatment of arterial hypertension. Transdermal (TD) CLO and oral CLO have comparable pharmacodynamics and therapeutic efficacy; the TD form has a reduced frequency of adverse effects. In patients with emesis, pain, gastrointestinal disorders, cognitive impairment, and dysphagia, TD drug delivery is the pharmacokinetic solution. CLO, within the "therapeutic range" of plasma concentration, is an agonist of alpha-2 adrenoreceptors (ATARs). The network of these receptors functions as an adaptive system, a vital link between the sympathoadrenergic system and multiple organs and systems. CLO activates this ATAR network and triggers transformations in cellular biology and in function of organs and systems. These reactions and responses increase resistance to stress/damage and protect the homeostasis. CLO enhances the adaptive response and is, therefore, an adaptogen. CLO and currently recognized phytoadaptogens cause similar changes in cellular signaling. CLO therapy is described by a new CLO-ATAR-adaptation concept. CLO therapy works within the ATAR network territory and makes adaptive sense. This concept explains successes of CLO therapy in diverse fields and its failures. It is ground for a prognosis on emerging therapeutic potential of TD CLO.
\end{abstract}

Keywords: transdermal delivery, delivery, clonidine, ATAR network, adaptation, potential

\section{Introduction}

Clonidine (CLO) was first introduced into clinical practice in 1962 as nasal decongestant and was later recognized as an antihypertensive agent. In 1974, the Food and Drug Administration approved CLO for the treatment of hypertension. In 1984, the transdermal (TD) form of CLO was approved by the Food and Drug Administration for the treatment of mild-to-moderate hypertension as monotherapy or in a combination with a diuretic. In the following years, both oral and TD CLO became popular in fields other than hypertension, ${ }^{1}$ such as substance withdrawal, posttraumatic stress disorder, movement disorders, sleep medicine, attention deficit disorder, psychiatric syndromes, anesthesia and analgesia, gastrointestinal ailments, and others. The breadth of applications of CLO is intriguing. This article is not a comprehensive review of TD CLO. It addresses pharmacokinetics and pharmacodynamics of TD CLO, physiological grounds of CLO therapy, advantages of TD CLO delivery and examines transformations in cellular biology and in function of organs and systems. This analysis will lead to a new concept of CLO therapy and to a prognosis on emerging therapeutic potential of TD CLO.

\section{Alpha-2 adrenoreceptor network}

Alpha adrenoreceptors are present on monoaminergic neurons and in other organs and systems. Alpha-1 receptors are postsynaptic; alpha-2 adrenoreceptors (ATARs) are both pre- and postsynaptic. 
ATAR is a trimeric (alpha, beta, and gamma subunits) transmembrane protein with extra- and intracellular domains. ATAR is one of G protein-coupled receptors. When bound to an agonist, the receptor protein comes into contact with the cytoplasmic $\mathrm{G}$ protein that binds to guanine nucleotides, to magnesium $\left(\mathrm{Mg}^{2+}\right)$, and to an effector. ${ }^{2-4}$ This transformation results in various intracellular processes. The major change is the inhibition of adenylate cyclase and decrease in conversion of adenosintriphosphate into cyclic adenosine monophosphate (cAMP). cAMP is on the "cross-roads" of cellular metabolism. It activates the protein kinase A (PKA) which stimulates lipase in adipocytes and glycogenolysis in myocytes and hepatocytes. ${ }^{5,6}$ Downregulation of adenylate cyclase and PKA activity presents a cellular shift from a catabolic to an anabolic state, it saves energy stored in adenosintriphosphate for anabolic reactions, function of mitochondria, and protection against toxins. ${ }^{7}$ In the prefrontal cortex (PFC), cAMP opens membrane channels and excessive opening of these channels, as it happens in stress, impairs cognition. Downregulation of cAMP production in the PFC may help cognitive functions. ${ }^{8}$ Other effectormediated cellular changes include acceleration of $\mathrm{Na}^{+} / \mathrm{H}^{+}$ exchange, ${ }^{9}$ activation of $\mathrm{K}^{+}$channels and hyperpolarization of the cellular membrane with suppression of neuronal firing and glandular secretion, ${ }^{10-12}$ inhibition of voltage-sensitive $\mathrm{Ca}^{2+}$ channels in nerve terminals blocking the release of neurotransmitters from vesicles into the synapse, ${ }^{13}$ and activation of phospholipase $\mathrm{C}$ with hydrolysis of phosphatidyl inositol into diacylglycerol and inositol triphosphate, ${ }^{14}$ the latter linked to cognition. Interestingly, ATARs are able to distinguish between noradrenaline (NA) stereoisomers and has a greater affinity to the L form (L-NA). ${ }^{15}$

The ATAR exist in three subtypes: $2 \mathrm{a}, 2 \mathrm{~b}$, and $2 \mathrm{c}^{16}$ and are found in multiple organs. ${ }^{17,18}$ The highest densities of ATAR are found in the hippocampus, amygdala, thalamus, locus coeruleus (LC), nucleus tractus solitarii and dorsal motor nucleus of the vagus, raphe nuclei, striatum, hypothalamus, limbic system, trigeminal nuclei, visceral sympathetic afferents, substantia gelatinosa of the spinal cord, descending serotonergic and noradrenergic pathways, lateral horns (intermediolateral column) of the thoracic spinal cord, nociceptive afferents, cardiovascular system, digestive system, and renal epithelium. The 2a receptors are found in the neural system and other organs, the $2 b$ receptors in the thalamus, and the $2 \mathrm{c}$ receptors mostly in the brain..$^{17,18}$

ATAR modulates both sympathetic and parasympathetic outflow. Presynaptic ATAR in the LC, in the nucleus reticularis lateralis, in the medulla, and on pre- and postganglionic sympathetic neurons function as autoreceptors sensing NA and providing negative feedback. ${ }^{19}$ Presynaptic ATAR in the vagal nuclei (dorsal motor nucleus, nucleus tractus solitarii) and on postganglionic parasympathetic neurons function as "control key" heteroreceptors and turn off parasympathetic reflexes, for instance, salivation, gastrointestinal (GI) motility, and secretion, at times of sympathoadrenergic (SA) activity. ${ }^{20-22}$ While stimulation of presynaptic ATAR in the SA system causes vasodilatation, stimulation of postsynaptic ATAR on blood vessels causes vasoconstriction. ${ }^{23,24}$ Activation of ATAR in the hypothalamus/pituitary stimulates release of growth hormone. ${ }^{25,26}$ Stimulation of ATAR in the pancreas inhibits secretion of insulin. ${ }^{27,28}$ ATARs are present on the network connecting sensory, limbic, neuroendocrine, motor systems, and higher brain regions. These ATARs are essential in brain connectivity and modulation of complex adaptive responses. ${ }^{29-32}$

\section{Transdermal CLO}

CLO is a mixed ATAR and alpha-1 adrenoreceptor agonist with greater (200:1) affinity to alpha-2 than to alpha-1 receptors. ${ }^{14}$ Within the "therapeutic range" of plasma concentration, $0.2-2.0 \mathrm{ng} / \mathrm{mL}$, CLO interacts with alpha-2 receptors, and at plasma levels $>2.0 \mathrm{ng} / \mathrm{mL}$, CLO interacts with alpha-1 receptors. ${ }^{33-35}$ TD CLO is a four-layer therapeutic system (TTS) with a thickness of $0.2 \mathrm{~mm}$, which releases CLO from a drug reservoir at a constant rate determined by a microporous membrane. ${ }^{36} \mathrm{An}$ increase in the size of the TTS leads to a proportional increase in the steady-state plasma concentrations..$^{37}$ The steady-state of CLO plasma concentration is achieved after 3-4 days of application and exists for at least 7 days. ${ }^{37}$ After removal of the TTS, CLO is still released from the skin depot for the next 3-4 days, and a therapeutic plasma level is maintained. ${ }^{37}$ In patients with hypertension, TTS that delivered from $0.1 \mathrm{mg}$ to $0.4 \mathrm{mg}$ of CLO a day provided therapeutic plasma levels of CLO $<2.0 \mathrm{ng} / \mathrm{mL} .{ }^{37-39}$ The steady-state plasma levels of CLO achieved with TTS is close to the trough levels achieved with equivalent daily amounts of orally administered $\mathrm{CLO}^{37,40}$ with absence of peak-to-trough variability. ${ }^{41}$ The elimination half-life of CLO in the TTS is $14-26$ hours, ${ }^{37} \sim 60 \%-70 \%$ of CLO is excreted unchanged by the kidneys with the remainder metabolized by the CYP450 system in the liver, ${ }^{42}$ where the 2D6 isoenzymes metabolize $60 \%-70 \%$ of the drug..$^{43}$ In plasma, only $20 \%$ of CLO is protein-bound. ${ }^{43}$

CLO stimulates presynaptic ATAR in the LC and medulla and causes sympathoinhibition marked by decrease in plasma NA concentration by $27 \%-36 \% .^{39,44,45}$ The therapeutic effects 
of oral and TD CLO are comparable, for instance, reduction in blood pressure (BP). ${ }^{46-49}$ TD CLO does not cause a sustained reduction in heart rate (HR) and cardiac output. ${ }^{45,50,51}$ Importantly, TD CLO does not affect the adaptive response to exercise when NA plasma concentration rises along with increase in $\mathrm{HR}$ and BP. ${ }^{51}$ Lower plasma CLO levels seen with use of TTS lead to reduction in undesired effects such as drowsiness, xerostomia, and sexual dysfunction. ${ }^{41,46,48,52}$ This decrease in adverse effects and a once-weekly dosing schedule improve compliance with treatment ${ }^{53,54}$ reaching $96 \%{ }^{55}$ and $99 \%{ }^{56}$

The frequency of skin reactions, such as erythema, induration, pruritis, and scaling, seen with TTS ranges from $9 \%$ to $52 \% .^{57,58}$ These untoward dermatological reactions usually resolve with patch removal; ${ }^{59}$ however, some patients may develop type IV hypersensitivity dermatitis that flares up with subsequent use of the oral formulation. ${ }^{60,61}$

The use of TD CLO led to a favorable change in the metabolic profile of patients with type 2 diabetes mellitus. ${ }^{62}$ The favorable metabolic changes included a reduction in fasting glucose levels, reduction in insulin resistance, and enhanced glucose utilization. In addition, treatment with TD CLO resulted in reduction in both microalbuminuria and fibrinogen levels. ${ }^{62}$

\section{CLO and emesis}

Activity of monoaminergic neurons was linked to emesis in animal studies. In pigeons, exposure to reserpine initially caused emesis via release of the monoamines, NA, and serotonin (5-hydroxytryptamine). Augmentation of this release by ATAR antagonists, yohimbine and idazoxan, promoted emesis, whereas ATAR agonists CLO and alphamethylnoradrenaline blocked their release and emesis. With continuous exposure to reserpine and depletion of monoamines, stimulation by yohimbine failed to cause emesis. ${ }^{63}$ In ferrets, emesis caused by phosphodiesterase 4 inhibitors was also augmented by yohimbine and blocked by CLO ${ }^{64}$ This is an example of interaction at the level of postreceptor effector mechanism. Phosphodiesterase 4 inhibitors increase intracellular content of cAMP, and blockade of ATAR by yohimbine augments this increase. CLO, in turn, causes reduction in intracellular cAMP by stimulating ATAR. ${ }^{64}$

CLO was used as an antiemetic in patients undergoing breast cancer surgery. ${ }^{65}$ Co-induction with midazolam and CLO vs midazolam with placebo led to a decreased need for anesthetics during surgery; postoperative nausea and vomiting were reduced from $67 \%$ of patients in the placebo group to $37 \%$ in the CLO group. The number needed to treat was low (3), and the cost was lower than cost of setrons.
No negative side effects were observed, postoperative sedation was not increased, and hemodynamic changes did not differ between the two groups. In children undergoing strabismus surgery, premedication with oral CLO reduced postoperative emesis. ${ }^{66}$ TD CLO provided significant reduction in emesis in CLONEMESI, a randomized, double-blind, and placebo-controlled pilot study of severe hyperemesis gravidarum. ${ }^{67}$ In CLONEMESI, systolic BP decreased by $6 \mathrm{~mm}$ and diastolic BP by $3 \mathrm{~mm}$. This study used a TD delivery system advantageous in emesis. The application of TD CLO was more frequent, every 5 days instead of every 7 days, which was based on faster CLO metabolism by the CYP450/2D6 system upregulated in pregnancy. ${ }^{43}$

\section{CLO and GI disorders}

The SA system and the ATAR modulate sensory and motor functions, fluid, and electrolyte transport in the GI tract. CLO, by interaction with ATAR in the GI tract, can help to correct altered sensation, motility, and fluid-electrolyte balance in functional and organic GI ailments. CLO can be used either stand alone or in conjunction with other treatments.

Oral CLO improved symptoms (bloating, nausea, vomiting) and gastric emptying time in a group of patients with diabetic autonomic neuropathy and gastroparesis. ${ }^{68}$ In this group, patients with diarrhea experienced improvement in stool consistency and frequency, while patients prone to constipation did not experience worsening of symptoms. There was no change in either glycemic control or hemodynamics. The mechanism of CLO success in these patients is not clear yet. In an experimental model, ${ }^{69}$ an alpha- 2 adrenergic agonist had an opposite effect; it caused gastroparesis explained by stimulation of heteroreceptors and parasympathetic deactivation. However, in patients with autonomic neuropathy, presynaptic targets are lost, and it is likely that CLO stimulated postsynaptic gastric muscle receptors.

Sensation of gas and pain in the colon and rectum is delivered by visceral sympathetic afferents traveling to the dorsal horns of the spinal cord. Stimulation of ATAR on efferent parasympathetic neurons (heteroreceptors) inhibits the release of acethylcholine. ${ }^{20,70}$ Stimulation of ATAR on enterocytes promotes absorption of water and electrolytes. ${ }^{71-73}$ In human volunteers, oral CLO caused colonic and rectal relaxation, increased compliance of the colon, ${ }^{74,75}$ and reduced perception of pain ${ }^{75,76}$ and gas. ${ }^{75}$ Increase in rectal compliance and reduced rectal sensitivity by TD CLO led to symptomatic improvement in women with fecal incontinence. ${ }^{77}$

Animal studies demonstrated the antidiarrheal effect of CLO and that it is caused by stimulation of ATAR 
on enterocytes. ${ }^{73,78,79}$ For instance, CLO blocked diarrhea caused by a variety of agents in mice. ${ }^{73}$ In a double-blind, placebo-controlled study, CLO provided relief of symptoms (stool frequency, consistency, and ease of passage) in patients with diarrhea-predominant irritable bowel syndrome. ${ }^{80}$ In case series, oral ${ }^{81}$ and TD $\mathrm{CLO}^{82}$ reduced fluid and sodium loss in patients with short bowel syndrome who failed other antidiarrheal agents. Oral CLO also significantly decreased the volume of diarrhea in three patients suffering from severe diabetic autonomic neuropathy. ${ }^{83}$ The decrease in sympathetic activity by TD CLO led to reduction in the disease activity score in patients with ulcerative colitis. ${ }^{84}$ CLO failed to reduce diarrhea in randomized controlled trial in patients with cholera. ${ }^{85}$ CLO was used in high dose, $0.9 \mathrm{mg} / 24 \mathrm{~h}$, but did not reduce fecal fluid loss. This battle between cholera toxin and CLO was lost on the intracellular postreceptor level. Cholera toxin produced enormous amounts of cAMP in the enterocytes that stimulated secretion, and stimulation of ATAR on enterocytes could not block the effect of the toxin.

\section{CLO and nociception}

ATARs are present on multiple levels along the nociceptive pathway. In the epidermis, ATARs are found on nociceptors. ${ }^{86}$ Sensitization of cutaneous nociceptors can trigger neuropathic pain, for instance, in painful diabetic neuropathy. ${ }^{87} \mathrm{In}$ a double-blind, randomized, placebo-controlled study, CLO gel ${ }^{88}$ was applied to the feet of patients with painful diabetic neuropathy. The antinociceptive effect was seen in patients with preserved and functional pain receptors. These patients had adequate density of $\mathrm{C}$ fibers on skin biopsy and demonstrated a painful response after application of a capscaicin patch. Since plasma concentration of CLO was negligible, the antinociceptive effect was attributed to stimulation of epidermal ATAR. In another randomized, double-blind, placebo-controlled study of patients with painful diabetic neuropathy, CLO TTS was superior to placebo, and the analgesic effect was not due to decrease in sympathetic outflow. Again, responders to CLO were preliminary selected in the first stage of the study and then compared to placebo in the second stage (enrichment enrollment design). ${ }^{89}$

ATARs are present in the dorsal horns of the spinal cord, ${ }^{17}$ where the first and second nociceptive neurons synapse. The ATARs are part of the descending inhibitory monoaminergic pathway. ${ }^{90}$ Stimulation of presynaptic ATAR inhibits release of substance P from axons of the first afferent neurons; ${ }^{91-93}$ stimulation of postsynaptic ATAR inhibits firing of the second neuron in the dorsal horn. ${ }^{94}$ The inhibitory pathway originates from the brainstem serotonergic raphe nuclei, ${ }^{95,96} \mathrm{LC}$ (coerulo-spinopetal system), and reticular formation in the lateral medulla. ${ }^{97,98}$ The descending monoaminergic system also contributes to the analgesic effect of opiates. ${ }^{99-102}$ The opiate receptors in the monoaminergic system are "upstream", located more centrally than the ATAR. ${ }^{103}$ Stimulation of the ATAR in the spinal cord by intrathecal infusion of CLO provided antinociception in patients after surgeries ${ }^{104}$ and in patients suffering from intractable malignant pain. ${ }^{105}$ The addition of CLO to an epidural regimen during labor resulted in a better analgesic effect, a reduction in doses of other analgesics, and a reduction in the incidence of pruritus. ${ }^{106}$ A combined regimen of TD and oral CLO was successfully used to control pain in a group of patients during and after elective abdominal surgery; ${ }^{107}$ however, it failed in another study. ${ }^{108}$ In the first group of patients, ${ }^{107}$ postoperative nausea and vomiting were reduced too. There are also mixed results in the use of TD CLO in the treatment of cluster headaches. In one group of patients, the frequency, duration, and intensity of headaches were reduced, ${ }^{109}$ whereas in another study, only some patients experienced relief of symptoms. ${ }^{110}$

It is interesting and needs to be further explained why the pain suppressing effect of CLO is selective and does not affect reception of other stimuli, for instance, mechanical and thermal. ${ }^{88,94}$ The application of TD CLO in various pain syndromes deserves further exploration. The receptor-based selection of potential responders used in patients with diabetic neuropathy ${ }^{88}$ is an attractive approach to CLO research and also merits attention.

\section{CLO and cognition}

Presynaptic ATAR in the $\mathrm{LC}$ and on its projections to other brain areas function as autoreceptors, preventing overactivity of the noradrenergic system and over-stimulation of brain areas. The majority of ATAR in the brain, however, are postsynaptic ${ }^{111}$ connecting the SA system with neuronal networks. The adrenergic system is essential in adaptation of the brain to an ever-changing environment ${ }^{112}$ and the interaction of CLO with postsynaptic ATAR enhances this adaptation. During a low arousal state, CLO promotes the deactivation of LC and the thalamus and reduces the functional integration between the thalamus and frontal cortex. Conversely, during a high arousal state requiring attention and working memory, CLO increases connectivity and the functional integration between LC, thalamus, parietal, and frontal cortex. ${ }^{113}$ CLO broadens the focus of attention, ${ }^{114}$ helps to filter information, and ignore distraction and irrelevant stimuli, ${ }^{114-116}$ improving cognitive functions based on noradrenergic input. ${ }^{112}$ 
CLO stimulates postjunctional $2 \mathrm{a}$ and $2 \mathrm{c}$ subtypes of ATAR in the PFC and its circuitry, ie, parietal cortex, hippocampus-amygdala complex, thalamus, and basal ganglia. This is the region of working memory, especially spatial memory, planning, executive function, ${ }^{117-121}$ cognitive flexibility, ability to solve problems, and search for solutions. ${ }^{122,123} \mathrm{CLO}$ improved working memory in normal young primates ${ }^{115,116}$ and in primates with catecholamine depletion that either occurred during normal aging ${ }^{18,124,125}$ or was chemically induced. ${ }^{126}$

CLO improved performance on spatial working memory task in human volunteers. ${ }^{127} \mathrm{CLO}$ improved cognitive function in patients with Korsakoff's psychosis, who were NA depleted by a lack of thiamine, essential for synthesis of NA in LC. ${ }^{128}$ In a study of patients with Alzheimer's disease, ${ }^{129}$ CLO in a dose-dependent manner improved functions linked to the PFC-parietal network, such as word fluency and spatial working memory. In another group of patients with Alzheimer's disease treated with CLO, various cognitive functions did not improve. ${ }^{130}$ Of note, CLO does not improve performance on tasks not linked to the PFC circuitry, ie, visual discrimination. ${ }^{118}$ During sleep, CLO decreases noradrenergic activity in the slow wave phase and blunts the influence of emotional charge of experience on memory consolidation, but overall, CLO does not impair retention of information. ${ }^{131}$

CLO improves performance of PFC-associated network by stimulation of postsynaptic ATAR. The noradrenergic system is a part of degeneration during aging ${ }^{132}$ and in brain disorders, for instance, Alzheimer's disease. ${ }^{133,134}$ The rules of receptor engagement depend on survival of noradrenergic neurons. In a brain with damaged noradrenergic pathways, low doses of CLO are adequate to stimulate postsynaptic receptors in the PFC. This scenario is analogous to the "paradoxical" effect of CLO in patients with severe orthostatic hypotension. ${ }^{135}$ In both cases, CLO interacts mostly with postjunctional ATAR: in the brain and in the blood vessels. In a brain with preserved noradrenergic system, higher doses of CLO are needed to stimulate receptors in the PFC. ${ }^{116,121,129}$ In patients with dementias, the anatomy and the extent of neuronal loss differ from person to person; multiple neurotransmitter systems are affected including sites of synthesis, projecting fibers, and receptor areas. As a result, response to treatment varies and the odds of improvement are lower with loss of receptor targets. And, since CLO is a mixed alpha-1 and alpha-2 agonist, stimulation of aplha-1 receptors may adversely affect treatment results. Ideally, selection of patients with a potential response to CLO would spare time, resources, and CLO reputation. It should resemble the targeted receptor-based approach used in patients with diabetic neuropathy. ${ }^{88}$ To date, however, there is no such screening tool yet. Would that be a CLO-based brain scan or alpha-2 brain mapping?

Sedating effect, caused by interaction of CLO with the $2 b$ subtype of ATAR in the thalamus, ${ }^{120}$ might prevent use of higher doses of CLO and interfere with attention requiring tasks. However, upon exposure to an agonist, the $2 \mathrm{~b}$ receptor subtype is more prone to downregulation than $2 \mathrm{a}$ and $2 \mathrm{c}$ subtypes. ${ }^{136,137}$ Then, sedation may be transient and the cognitive benefit gained by sustained stimulation of $2 \mathrm{a}$ and $2 \mathrm{c}$ receptors would dominate. Accordingly, a prolonged exposure rather than a single-dose administration is desirable for learning the benefits of CLO.

Of interest are reports of neuropsychiatric applications of CLO, for instance, in manic episodes of bipolar disorder, ${ }^{138}$ in anxiety, ${ }^{139}$ and in neuroleptic-induced movement disorders. ${ }^{140-143}$ Clearly, in a psychotic and noncompliant patient, the TD route of drug delivery is an attractive pharmacokinetic option.

\section{Pharmacokinetic solution}

We reviewed some of the nontraditional, noncardiovascular therapeutic applications of CLO. Antiemetic properties of CLO are very interesting and likely based on stimulation of ATAR on both noradrenergic and serotonergic neurons and inhibition of NA and 5-hydroxytryptamine release. ${ }^{63,144} \mathrm{CLO}$ is valuable in functional and organic GI disorders either as monotherapy or as an adjunct to other treatments. CLO interacts with nociceptive pathways on multiple levels and that makes it useful in various pain syndromes. Brain disorders are very complex, and cognitive effects of CLO, overall encouraging, call for further research. In all these fields: nausea and emesis with inability to tolerate oral medicines; GI disorders with altered motility and absorption; pain syndromes treated with complex drug regimens; impaired cognition and nonadherence to treatment; the TD route of drug delivery (TD CLO) is the pharmacokinetic solution. The TD route is also advantageous in patients with swallowing dysfunction, where TD CLO can be used as an antisialogogue $\mathrm{e}^{145}$ and with other therapeutic goals.

As noted earlier, pharmacodynamics of oral CLO and TD CLO are comparable. Therefore, the therapeutic potential of TD CLO matches that of oral CLO. Moreover, in certain circumstances, TD drug delivery is either the better or even the only option and, therefore, the pharmacokinetic solution.

\section{Adaptive response}

The acute adaptive response to external stressors, identified as the "fight and flight" reaction, is a complex of 
well-coordinated physiological processes in multiple organ systems. LC is "fired up"; traffic in the descending and in the ascending adrenergic pathways is substantially increased, however, meticulously self-controlled. Sympatho-inhibition, a self-control mechanism, affects the basal sympathetic tone and leaves the adaptive response preserved. ${ }^{51}$ Brain areas are integrated, level of vigilance is raised, input of information is filtered, and spatial orientation, working memory, and executive function are maximized. The BP and HR are raised, increase in secretion of growth hormone and suppression of insulin release assure higher serum glucose level. Pain is suppressed. Parasympathetic "rest and digest" reflexes are turned off. The adaptive response is carried out by the SA system, the connecting ATAR network/system, and effector organs. The ATARs are involved in sensory perception, modulation of autonomic output, brain integration, and accomplishment of high neural functions. The ATAR system presents a very wisely designed, strategically placed adaptive network connecting the SA system to other organs and systems.

Adaptation, however, is broader than response to external stressors; it also entails damage repair mechanisms. Adaptation is self-repair of noxious processes and self-control of unpleasant symptoms, for instance, correction of gastric motility in gastroparesis and control of nausea, correction of intestinal secretion to stop diarrhea and modulation of afferent input from the GI tract to decrease sensation of pain and gas. The two adaptive systems, the SA system and the ATAR system, guide the adaptation, the adaptive repair, and symptom control.

\section{TD CLO as an adaptogen}

Success of oral and TD CLO therapy in diverse clinical fields appears at first puzzling and intriguing. Certainly, CLO is not a panacea, it has failures, too. So, what is CLO?

CLO therapy can be described by a new, CLO-ATARadaptation (CL-ATAR-AD) concept. CLO "turns on" the ATAR system and sets off adaptive reactions and responses associated with these receptors. CLO, therefore, is a remedy "increasing resistance to a broad spectrum of stressors of different physical, chemical and biological natures", ${ }^{146}$ where a stressor is a threat to homeostasis. ${ }^{147}$ Such remedy/agent is called an adaptogen. The concept of adaptogens, currently all of plant origin, has been recognized by the scientific community. ${ }^{148}$ It is interesting but not surprising that both CLO and phytoadaptogens cause similar changes in cellular signaling: phytoadaptogens ${ }^{149}$ also decrease the amount of cAMP, increase phospholipase $\mathrm{C}$ activity, and reduce the number of $\mathrm{G}$ protein-coupled receptors including the ATAR. The latter prevents their overwhelming and disorganizing stimulation by stress. ${ }^{150}$ The phytoadaptogens cause these changes by activating or deactivating certain genes. ${ }^{149}$ In author's opinion, these similarities in the molecular and cellular transformations further support classifying CLO as an adaptogen.

The CL-ATAR-AD concept implies "sense and territory". The ATAR system assures the "adaptive sense" of CLO therapy and delineates its therapeutic territory, as vast and as limited as the ATAR network. The ATAR system is "smart" and flexible, as it is required for adaptation. For instance, in patients with orthostatic hypotension, ${ }^{135}$ postjunctional receptors are activated and BP rises. Secretion of growth hormone ${ }^{25,26}$ and suppression of insulin secretion ${ }^{27,28}$ maintain the level of glucose, but utilization of glucose by tissues is also improved. ${ }^{62}$ Correction of gastroparesis ${ }^{68}$ is achieved through a not yet understood mechanism. CLO therapy, however, cannot succeed if the damage is beyond ATAR land or if the damage is overwhelming and irreparable through ATAR associated mechanisms. As an example, in a patient with dementia and atrophy of the PFC, CLO might not improve cognition. The cholera toxin produced intracellular cAMP in such enormous amounts that stimulation of ATAR could not counteract it and control secretory diarrhea. ${ }^{85}$ The CLO-ATAR-adaptation concept also encourages a prognosis on emerging therapeutic potential of TD CLO. As already noted, the therapeutic potential of TD CLO at least matches that of oral CLO. The field of future TD CLO applications lies within the adaptive ATAR network. TD CLO can be used as stand alone or with other treatments. The physiological task would be consistent with resistance to damage and protection of homeostasis and could be as bold as declared for phytoadaptogens: aging, neurodegeneration, inflammation, immunity, drug toxicities, and many others. ${ }^{149}$ Gains that need time and are not easily measurable. Yes, the breadth of the current data is intriguing but makes adaptive sense. Hence, it is encouraging and promising. The story continues and will learn more about TD CLO.

\section{Conclusion}

CLO, an agonist of alpha receptors, is used in oral and TD forms. Both forms of CLO are equally effective; the TD form has attractive pharmacokinetics and a lesser burden of adverse effects. In certain clinical circumstances, for instance, in patients with dysphagia, nausea, GI ailments, cognitive disorders, and complex pain syndromes, the TD route of drug delivery (TD CLO) is the pharmacokinetic solution. The ATAR network is an adaptive system connecting the sympatho-adrenergic system to other organs, systems, and organ systems. CLO activates this adaptive system and 
triggers reactions and responses of adaptation protecting the homeostasis. For this reason, CLO is an adaptogen and CLO therapy can be described by a new CLO-ATAR-adaptation concept. This concept explains successes and failures of CLO therapy in diverse clinical fields. It also lays grounds for a prognosis on emerging therapeutic potential of TD CLO and encourages further research on TD CLO, expectantly interesting and fruitful.

\section{Acknowledgments}

The author is grateful to librarians Arpita Bose and Yvette Walton for their kind assistance.

\section{Disclosure}

The author reports no conflicts of interest in this work.

\section{References}

1. Pagan N, Wargo K, Malone P, et al. The Clinical Utility of Clonidine. Vol 5. Congers, NY: US Pharm; 2006:HS-2-HS16.

2. Gilman A. G proteins: transducers of receptor-generated signals. Annu Rev Biochem. 1987;56:615-649.

3. Neer E, Chapham D. Roles of G protein subunits in transmembrane signaling. Nature. 1988;333:129-134.

4. Freissmuth M, Casey P, Gilman A. G proteins control diverse pathways of transmembrane signaling. FASEB J. 1989;3:2125-2131.

5. Lilmbrid L. Receptors linked to inhibition of adenylate cyclase: additional signaling mechanisms. FASEB J. 1988;2:2686-2695.

6. Walsh D, van Patten S. Multiple pathway signal transduction by the cAMP-dependent protein kinase. FASEB J. 1994;8:1227-1236.

7. Chiu P, Leung H, Ko K. Schizandrin B enhances renal mitochondrial antioxidant status, functional and structural integrity, and protects against gentamicin-induced nephrotoxicity in rats. Biol Pharm Bull. 2008;31:602-605.

8. Wang M, Ramos BP, Paspalas CD, et al. Alpha 2A adrenoreceptors strengthen working memory networks by inhibiting cAMP -HCN channel signaling in prefrontal cortex. Cell. 2007;129:397-410.

9. Isom L, Cragoe E, Limbrid L. alpha-2 adrenergic receptors accelerate $\mathrm{Na}+\mathrm{H}+$ exchange in neuroblastoma $\mathrm{x}$ glioma cells. $J$ Biol Chem. 1987;262:6720-6787.

10. Aghajanian G, Vander-Maelen C. Alpha 2-adrenoreceptor - mediated hyperpolarization of locus coeruleus neurons: intracellular studies in vivo. Science. 1982;215:1394-1396.

11. Egan TM, Henderson G, North RA, Williams JT. Noradrenalin mediated synaptic inhibition in rat locus coeruleus neurons. $J$ Physiol. 1983;345:477-488.

12. Schoffelmeer A, Mudler A. Presynaptic opioid receptor and alpha-2 adrenoreceptor mediated inhibition of noradrenaline release in the rat brain. Role of hyperpolarization? Eur J Pharmacol. 1984;105: 129-135.

13. Williams J, North R. Catecholamine inhibition of calcium action potentials in rat locus coeruleus neurons. Neuroscience. 1985;14:105-109.

14. Maze M, Tranquilli W. Alpha-2 adrenoreceptor agonists: defining the role in clinical anesthesia. Anesthesiology. 1991;74:581-605.

15. U'Prichard D, Greenberg D, Snyder S. Binding characteristics of a radiolabeled agonist and antagonist at central nervous system alpha noradrenergic receptors. Mol Pharmacol. 1976;13:454-473.

16. Bylund D. Subtypes of alpa-2 adrenoreceptors. Pharmacological and biological evidence converge. Trends Pharmacol Sci. 1988;9:356-361.

17. Unnerstall J, Kopajtic T, Kuhar M. Distribution of alpha 2 agonist binding sites in the rat and human central nervous system: analysis of some functional, anatomic correlates of the pharmacologic effects of clonidine and related adrenergic agents. Brain Res Rev. 1984;7:69-101.
18. Saunders C, Limbrid L. Lacalization and trafficking of a-2 adrenergic receptor subtypes in cells and tissues. Pharmacol Ther. 1999;84: 193-205.

19. Starke K, Gotheri M, Kiblinger H. Modulation of neurotransmitter release by presynaptic autoreceptors. Physiol Rev. 1989;69:864-889.

20. Drew G. Pharmacological characterization of presynaptic a-adrenoreceptors regulating cholinergic activity in the guinea pig ileum. $\mathrm{Br} J$ Pharmacol. 1978;64:293-300.

21. Wikberg J. Localization of adrenergic receptors in guinea pig ileum and rabbit jejunum to cholinergic neurons and to smooth muscle cells. Acta Physio Scand. 1977;99:190-207.

22. Izumi H, Nakamura I, Karita K. Effects of clonidine and yohimbine on parasympathetic salivation and vasodilatation in cat SMG. Am J Physiol. 1995;268:R1196-R1202.

23. Starke K, Montel H, Gayk W, Merker R. Comparison of the effects of clonidine on pre- and postsynaptic adrenoreceptors in the rabbit pulmonary artery. Naunyn Schmiedebergs Arch Pharmacol. 1974;285:133-150.

24. Ruffolo R. Distribution and function of peripheral alpha - adrenoreceptors on the cardiovascular system. Pharmacol Biochem Behav. 1985;22:327-333.

25. Eriksson E, Eden S, Modigh K. Inportance of norepinephrine alpha 2 receptor activation for morphine induced ratbgrowth hormone secretion. Neuroendocrinology. 1981;33:91-96.

26. Grossman A, Weerasuriya K, Al-Damluji S. Alpha-2 adrenoreceptor agonists stimulate growth hormone secretion but have no acute effects on plasma cortisol under basal conditions. Horm Res. 1987;25:65-71.

27. Garcia-Morales P, Dufrane SP, Sener A, Valverde I, Malaisse WJ. Inhibitory effect of clonidine upon adenylate cyclase activity, cyclic AMP production and insulin release in rat pancreatic islets. Biosci Rep. 1984;4:511-521.

28. Angel I, Langer S. Adrenergic induced hyperglycemia in anesthesized rats: involvement of peripheral alpha 2 - adrenoreceptors. Eur $J$ Pharmacol. 1988;154:191-196.

29. Mogenson G, Jones D, Yim C. From motivation to action: functional interface between the limbic system and the motor system. Prog Neurobiol. 1980;14:69-97.

30. Nauta W, Domesick V. Neural associations of the limbic system. In: Beckman AL, editor. The Neural Basis of Behavior. Hicksville, NY: Spectrum Publications, Inc.; 1982:175-206.

31. Swanson L, Mogenson G. Neural mechanisms for the functional coupling of autonomic, endocrine and somatomotor responses in adaptive behavior. Brain Res Rev. 1981;3:1-34.

32. Coull JT, Frith CD, Dolan RJ, Frackowiak RS, Grasby PM. The neural correlates of the noradrenergic modulation of human attention, arousal and learning. Eur J Neurosci. 1997;9:589-598.

33. Dollery CT, Davies DS, Draffan GH, et al. Clinical pharmacology and pharmacokinetics of clonidine. Clin Pharmacol Ther. 1976;19(1): $11-17$.

34. Reid J, Barber N, Davies D. The clinical pharmacology of clonidine: relationship between plasma concentration and pharmacological effect in animals and men. Arch Int Pharmacodyn Ther. 1980;(Suppl):11-16.

35. Frisk-Holmberg M, Faizlow L, Wibell L. Relationship between the cardiovascular effects and steady-state kinetics of clonidine in hypertension. Eur J Clin Pharmacol. 1984;26:309-313.

36. Shaw J, Enscore D, Chu L. Clonidine rate-controlled system: technology and kinetics. In: Weber MA, Mathias CJ, editors. Mild Hypertension. Proceedings of the International Titisee Workshop. Darmstadt: Steinkopff Verlag; 1984:134-140.

37. MacGregor TR, Matzek KM, Keirns JJ, van Wayjen RG, van den Ende A, van Tol RG. Pharmacokinetics of transdermally delivered clonidine. Clin Pharmacol Ther. 1985;38:278-284.

38. Weber M, Drayer J, Brewer D, Lipson JL. Transdermal continous antihypertensive therapy. Lancet. 1984;1:9-11.

39. Klein C, Morton N, Kelley S, Metz S. Transdermal clonidine therapy in elderly mild hypertensives: effect on blood pressure, plasma, norepinephrine and fasting plasma glucose. J Hypertens Suppl. 1985;3: S81-S84. 
40. Weber M. Transdermal antihypertensive therapy: clinical and metabolic considerations. Am Heart J. 1986;112:905-912.

41. McChesney J, Ryan C, Shaw R, Fishman-Rosen J, Murphy MC. Transdermal clonidine for the treatment of essential hypertension. Compr Ther. 1987;13:49-53.

42. Arndts D, Doevendans J, Kirsten R, Heintz B. New aspects of the pharmacokinetics and pharmacodynamics of clonidine in man. Eur $J$ Clin Pharmacol. 1983;24:21-30.

43. Claessens AJ, Risler LJ, Eyal S, Shen DD, Easterling TR, Hebert MF. CYP2D6 mediates 4-hydroxylation of clonidine in vitro: implication for pregnancy-induced changes in clonidine clearance. Drug Metab Dispos. 2010;38:1393-1396.

44. Schaller M, Nussberger J, Weber B. Transdermal clonidine therapy in hypertensive patients. JAMA. 1985;253:233-235.

45. Golub M, Thananopavarn C, Sambhi M. Transdermal clonidine in elderly patiemts with mild hypertension: effects on blood pressure and catecholamines. In: Weber MA, Drayer JIM, editors. Low Dose Oral and Transdermal Therapy of Hypertension. International Symposium on Clonidine in Hypertension. Darmstadt: Steinkopff Verlag; 1985:16-21.

46. Popli S, Stroka G, Ing TS, et al. Transdermal clonidine for hypertensive patients. Clin Ther. 1983;5:624-628.

47. Gosse P, Wicker P, Roudaut R, Danays T, Dallocchio M. Treatment of hypertension by a new transdermal form of clonidine. J Hypertension. 1985;3:565-567.

48. Burris J, Mroczek W. Transdermal administration of clonidine: a new approach to antihypertensive therapy. Pharmacotherapy. 1986;6: 30-34.

49. Hollifield J. Clinical acceptability of transdermal clonidine: a large scale evaluation by practitioners. Am Heart J. 1986;112:900-906.

50. Houston M. Clonidine hydrochloride: review of pharmacologic and clinical aspects. Prog Cardiovasc Dis. 1981;23:337-350.

51. Kolloch R, Finster H, Overlack A, et al. Low dose oral and transdermal application of clonidine in mild hypertension: hemodynamic and biochemical correlates. In: Weber MA, Drayer JIM, Kolloch R, editors. Low Dose Oral and Transdermal Therapy of Hypertension. International Symposium on Clonidine in Hypertension. Darmstadt: Steinkopff Verlag; 1985:71-80.

52. Fillingim JM, Matzek KM, Hughes EM, Johnson PA, Sharon GS. Long term treatment with transdermal clonidine in mild hypertension. Clin Ther. 1989;11:398-408.

53. Sclar DA, Skaer TL, Chin A, Okamoto MP, Gill MA. Utility of transdermal delivery system for antihypertensive therapy. Am J Med. 1991;91(1A):50S-56S.

54. Ross E, Pittman T, Koo L. Strategy for the treatment of noncompliant hypertensive hemodyalysis patients. Int J Artif Organs. 2002;25: 1061-1065.

55. Burris JF, Papademetriou V, Wallin JD, Cook ME, Weidler DJ. Therapeutic adherence in the elderly: transdemal clonidine compared to oral verapamil for hypertension. Am J Med. 1991;91(Suppl 1A):22S-28S.

56. McMahon FG, Jain AK, Vargas R, Fillingim J. A double - blind comparison of transdermal clonidine and oral captopril in essential hypertension. Clin Ther. 1990;12:88-100.

57. Kellaway G, Lubbe W. A community - based trial of transdermal antihypertensive therapy with clonidine (Catapres - TTS). N Z Med J. 1986;99:711-714.

58. Burris J. Transdermal clonidine dermatitis. JAMA. 1987;258: 1819-1820.

59. Groth H, Greminger P, Vetter H, Knüsel J, Baumgart P, Siegenthaler W. Transdermal clonidine: a new approach to therapy in essential hypertension. Schweizerishe Rundshau fur Medizin Praxis. 1985;74:10-14.

60. Maibach H. Clonidine irritant and allergic contact dermatitis assays. Contact Dermatitis. 1985;12:192-195.

61. Maibach H. Oral substitution in patients sensitized by transdermal clonidine treatment. Contact Dermatitis. 1987;16:1-8.

62. Giugliano D, Acampora R, Marfella R, et al. Hemodynamic and metabolic effects of transdermal clonidine in patients with hypertension and non-insulin-depenedent diabetes mellitus. Am J Hypertens. 1998;11:184-189.
63. Khandker SK, Mukerjee D, Gurtu S, Pant KK, Dhawan KN, Sinha JN. Modification of reserpine - induced emetic response in pigeons by a2-adrenoreceptors. Pharmacol Res. 1994;29(4):383-387.

64. Robichaud A, Savoie C, Stamatiou PB, Tattersall FD, Chan CC. PDE4 inhibitors induce emesis in ferrets via a noradrenergic pathway. Neuropharmacology. 2001;40:262-269.

65. Oddby-Muhrbeck E, Eksborg S, Bergendahl HT, Muhrbeck O, Lönnqvist PA. Effects of clonidine on postoperative nausea and vomiting in breast cancer surgery. Anesthesiology. 2002;96:1109-1114.

66. Mikawa K, Nishina K, Maekawa N, Asano M, Obara H. Oral clonidine premedication reducesvomiting in children after strabismus surgery. Can J Anaesth. 1995;4:977-981.

67. Maina A, Arrotta M, Cicogna L, et al. Transderma clonidine in the treatment of severe hyperemesis. A pilot randomised control trial: CLONEMESI. BJOG. 2014;121(12):1556-1562.

68. Rosa-e-Silva L, Troncon LE, Oliveira RB, Iazigi N, Gallo L Jr, Foss MC. Treatment of diabetic gastroparesis with oral clonidine. Aliment Pharmacol Ther. 1995;9:179-183.

69. Gullikson GW, Virina MA, Loeffler R, Erwin WD. Alpha-2 - adrenergic model of gastroparesis: validation with renzapride, a simulator of motility. Am J Physiol. 1991;261:G426-G432.

70. Tack J, Wood J. Actions of noradrenaline on myenteric neurons on the guinea pig gastric antrum. J Auton Nerv Syst. 1992;41:67-78.

71. Chang E, Field M, Miller R. Alpha-2 adrenergic receptors regulation of ion transport in rabbit ileum. Am J Physiol. 1982;242:G237-G242.

72. Chang E, Field M, Miller R. Enterocyte alpha-2 adrenergic receptors: yohimbine and p-aminoclonidine binding relative to ion transport. Am J Physiol. 1983;244:G75-G82.

73. Doherty N, Hancock A. Role of alpha-2 adrenergic receptors in the control of diarrhea and intestinal motility. J Pharmacol Exp Ther. 1983;225:269-274

74. Schiller LR, Santa Ana CA, Morawski SG, Fordtran JS. Studies of the antidiarrheal action of clonidine. Gastroenterology. 1985;89: 982-988.

75. Viramontes BE, Malcolm A, Camilleri M, et al. Effects of an a2 adrenergic agonist on gastrointestinal transit, colonic motility, and sensation in humans. Am J Physiol Gastrointest Liver Physiol. 2001;281: G1468-G1476.

76. Bharucha AE, Camilleri M, Zinsmeister AR, Hanson RB. Adrenergic modulation of human colonic motor and sensory function. Am J Physiol. 1997;273:G997-G1006.

77. Brarucha A, Seide B, Zinmeister A. Effect of clonidine on symptoms and anorectal sensorimotor function in women with fecal incontinence. Ailment Pharmacol Ther. 2010;32(5):681-688.

78. Durbin T, Rosenthal L, McArthur K, Anderson D, Dharmsathaphorn K. Clonidine and lidamidine stimulate sodium and chloride absorption in the rabbit intestine. Gastroenterology. 1982;82:1352-1358.

79. Sundaram U. Mechanism of intestinal absorption: effect of cloninide on rabbit ileal villus and crypt cells. J Clin Invest. 1995;95: 2187-2194.

80. Camilleri M, Kim DY, McKinzie S, et al. A randomized, controlled exploratory study of clonidine in diarrhea-predominant irritable bowel syndrome. Clin Gastroenterol Hepatol. 2003;1:111-121.

81. McDoniel K, Taylor B, Huey W, et al. Use of clonidine to decrease intestinal fluid losses in patients with high-output short - bowel syndrome. JPEN J Parenter Enteral Nutr. 2004;28:265-268.

82. Buchman AL, Fryer J, Wallin A, Ahn CW, Polensky S, Zaremba K. Clonidine reduces diarrhea and sodium loss in patients with proximal jejunostomy: a controlled study. JPEN J Parenter Enteral Nutr. 2006;30:487-491.

83. Fedorak R, Field M, Chang E. Treatment of diabetic diarrhea with clonidine. Ann Intern Med. 1985;102:197-199.

84. Furlan R, Ardizzone S, Palazzolo L, et al. Sympathetic overactivity in active ulcerative colitis: effects of clonidine. Am J Physiol Regul Integr Comp Physiol. 2006;290(1):R224-R232.

85. Rabbani G, Butler T, Patte D, et al. Clinical trial of clonidine hydrochloride as an antisecretory agent in cholera. Gastroenterology. 1989;97(2):321-325. 
86. Riedl MS, Schnell SA, Overland AC, et al. Coexpression of alpha-2 adrenergic and delta-opioid receptors in substance P-containing terminals in rat dorsal horn. J Comp Neurol. 2009;513:385-398.

87. Campbell J, Meyer R. Mechanisms of neuropathic pain. Neuron. 2006;52:77-92

88. Campbell CM, Kipnes MS, Stouch BC, et al. Randomized control trial of topical clonidine for treatment of painful diabetic neuropathy. Pain. 2012;153(9):1815-1823.

89. Byas-Smith M, Max M, Muir J. Transdermal clonidine compared to placebo in painful diabetic neuropathy using a two-stage "enriched enrollment" design. Pain. 1995;60:267-274.

90. Zemlan F, Corrigan S, Pfaff D. Noradrenergic and serotonergic mediation of spinal analgesia mechanisms. Eur J Pharmacol. 1980;61: 111-124.

91. Kuraishi Y, Harada Y, Takagi H. Noradrenaline regulation of pain transmission in the spinal cord mediated by a-adrenoreceptors. Brain Res. 1979;174:333-336.

92. Kuraishi Y, Hirota N, Sato Y, et al. Transmission of pain information and neuropeptides - with special reference to substance $\mathrm{P}$ in the primary afferents. Jpn J Pharmacol. 1984;34(Suppl):38.

93. KuraishiY, Hirota N, Sato Y, Kaneko S, Satoh M, Takagi H. Noradrenergic inhibition of the release of substance $\mathrm{P}$ from the primary afferents in the rabbit spinal dorsal horn. Brain Res. 1985;359:177-182.

94. Fleetwood-Walker SM, Mitchell R, Hope PJ, Molony V, Iggo A. An a-2 receptor mediates the selective inhibition by noradrenaline of nociceptive responses of identified dorsal horn neurones. Brain Res. 1985;334:243-254

95. Kuraishi Y, Fukui K, Shiomi H, Akaike A, Takagi H. Microinjection of opioids into the nucleus reticularis gigantocellularisof the rat analgesia and increase in the normetanephrine level in the spinal cord. Biochem Pharmacol. 1978;27:2756-2758.

96. Yaksh T. Direct evidence that spinal serotonin and adrenaline terminals mediate the spinal antinociceptive effects of morphine in the periaqueductal gray. Brain Res. 1979;160:180-185.

97. Yaksh T, Hammond D, Tyce G. Functional aspects of bulbospinal monoaminergic projections in modulating processing of somatosensory information Fe ? Fed Proc. 1981;40:2786-2794.

98. Morton C, Johnson S, Duggan A. Lateral reticular regions and the descending control of dorsal horn neurons of the cat: selective inhibition by electrical stimulation. Brain Res. 1983;275:13-21.

99. Kuraishi Y, Harada Y, Aratani S, Satoh M, Takagi H. Separate involvement of the spinal noradrenergic and serotonergic systems in morphine analgesia: the differences in mechanical and thermal analgesic tests. Brain Res. 1983;273:245-252.

100. Kuraishi Y, Hirota N, Sugimoto M, Satoh M, Takagi H. Effects of morphine on noxious stimuli -induced release of substance P from rabbit dorsal horn in vivo. Life Sci. 1983;33(Suppl 1):693-696.

101. Shiomi H, Takagi H. Morphine analgesia and the bulbospinal noradrenergic system: increase in the concentration of normetanephrine in the spinal cord of the rat caused by analgesics. Br J Pharmacol. 1974;52:519-526.

102. Takagi H, Shiomi H, Kuraishi Y, Fukui K, Ueda H. Pain and the bulbospinal noradrenergic system: pain induced increase in normetanephrine content in the spinal cord and its modification by morphine. Eur J Pharmacol. 1979;54:99-107.

103. Osipov M, Suarez L, Spaulding T. Antinociceptive interactions between alpha-2 adrenergic and opiate agonists at the spinal level in rodents. Anesth Analg. 1989;68:194-200.

104. Eisenach J, Lysack S, Viscomi C. Epidural clonidine analgesia following surgery: phase 1. Anesthesiology. 1989;71:640-646.

105. Eisenach J, Rauck L, Buzzanell C, et al. Epidural clonidine analgesia for intractable cancer pain: phase 1. Anesthesiology. 1989; 71:647-652.

106. Wallet F, Clement H, Bouret C. Effects of a continuous low-dose clonidine epidural regimen on pain, satisfaction and adverse events during labour: a randomized, double - blind, placebo-controlled trial. Eur J Anaesthsiol. 2010;27:441-447.
107. Segal IS, Jarvis DJ, Duncan SR, White PF, Maze M. Clinical efficacy of oral-transdermal clonidine conbinations during the perioperative period. Anesthesiology. 1991;74:220-225.

108. Owen MD, Fibuch EE, McQuillan R, Millington WR. Postoperative analgesia using a low-dose, oral-transdermal clonidine combination: lack of clinical efficacy. J Clin Anesth. 1997;9:8-14.

109. D’Andrea G, Perini F, Granella F, Cananzi A, Sergi A. Efficacy of transdermal clonidnie in short-term treatment of cluster headache: a pilot study. Cephalalgia. 1995;15:430-433.

110. Leone M, Attanasio A, Grazzi L, et al. Transdermal clonidine in the prophylaxis of episodic cluster headache: an open study. Headache. 1997;37:559-560.

111. Aoki C, Go CG, Venkatesan C, Kurose H. Perikaryal and synaptic localization of a -2a-adrenergic receptor- like immunoreactivity. Brain Res. 1994;650:181-204.

112. Arnsten A, Steere J, Hunt R. The contribution on a-2 noradrenergic mechanisms to prefrontal cognitive function. Arch Gen Psychiatry. 1996;53(5):448-455.

113. Coull JT, Büchel C, Friston KJ, Frith CD. Noradrenergically mediated plasticity in a human attentional neuronal network. Neuroimage. 1999; 10:710-715.

114. Coull JT, Middleton HC, Robbins TW, Sahakian BJ. Differential effects of clonidine, haloperidol, diazepam and tryptophan depletion on focused attention and attentional search. Psychopharmacology. 1995;121:222-230.

115. Jackson W, Buccafusco J. Clonidine enhances delayed matching to - sample performance by young and aged monkeys. Pharmacol Biochem Behav. 1991;39:79-84.

116. Franowicz J, Phil M, Arnsten A. Treatment with the noradrenergic alpha-2 agonist clonidine, but not doazepam, improves spatial working memory in normal young rhesus monkeys. Neuropsychopharmacology. 1999;21:611-621.

117. Brozoski TJ, Brown RM, Rosvold HE, Goldman PS. Cognitive deficit caused by regional depletion of dopamine in the prefrontal cortex of the rhesus monkey. Science. 1979;205:929-932.

118. Arnsten A, Goldman - Rakic P. Alpha-2 adrenergic mechanisms in prefrontal cortex associated with cognitive decline in aged nonhuman primates. Science. 1985;230:1273-1276.

119. Owen AM, Downes JJ, Sahakian BJ, Polkey CE, Robbins TW. Planning and spatial working memory following frontal lobe lesions in man. Neuropsychologia. 1990;28(10):1021-1034.

120. Coull JT. Neural Correlates of Attention and Arousal. Insights from Electrophysiology, Functional Neuroimaging and Psychopharmacology. Prog in Neurobiology. 1998;55:343-351.

121. Arnsten A, Li B. Neurobiology of executive functions: cathecholamine influences on prefrontal cortical functions. Biol Psychiatry. 2005;57: 1377-1384.

122. Beversdorf DQ, Hughes JD, Steinberg BA, Lewis LD, Heilman KM. Noradrenergic modulation of cognitive flexibility in problem solving. Neuroreport. 1999;10:2763-2767.

123. Silver JA, Hughes JD, Bornstein RA, Beversdorf DQ. Effect of anxiolytics on cognitive flexibility in problem solving. Cogn Behav Neurol. 2004;17:93-97.

124. Arnsten A, Goldman-Rakic P. Analysis of alpha-2 adrenergic agonist effects on the delayed nonmatch-to-sample performance of aged rhesus monkeys. Neurobiol Aging. 1990;11:583-590.

125. Arnsten A, Contant T. Alpha-2 adrenergic agonists decrease distractibility in aged monkeys performimg the delayed response task Psychopharmacology. 1992;108:159-169.

126. Cai J-X, Ma Y, Hu X. Reserpine impairs spatial working memory performance in monkeys: reversal by the a- 2 adrenergic agonist clonidine. Brain Res. 1993;614:191-196.

127. Coull JT, Middleton HC, Robbins TW, Sahakian BJ. Contrasing effects of clonidine and diazepam on tests of working memory and planning Psychopharmacology. 1995;120(3):311-321.

128. Mair R, McEntee W. Cognitive enhancement in Korsakoff's psychosis by clonidine: a comparison with L-Dopa and Ephedrine. Psychopharmacology. 1986;88:374-380. 
129. Riekkinen P, Riekkinen M. THA improves word planning and clonidine enhances fluency and working memory in Alzheimer's disease. Neuropsychopharmacology. 1999;20:357-364.

130. Mohr E, Schlegel J, Fabbrini G, et al. Clonidine treatment of Alzheimer's disease. Arch Neurol. 1989;46:376-378.

131. Groch S, Wilhelm I, Diekelmann S, Sayk F, Gais S, Born J. Contribution of norepinephrine to emotional memory consolidation during sleep. Psychoneuroendocrinology. 2011;36:1342-1350.

132. Bondareff W, Mountjoy C, Roth M. Loss of neurons of origin of the adrenergic projection to cerebral cortex (nucleus locus coeruleus) in senile dementia. Neurology. 1982;32:164-168.

133. Perry E, Tomlinson B, Blessed G, Perry RH, Cross AJ, Crow TJ. Neuropathological and biochemical observations on the noradrenergic system in Alzheimer's disease. J Neurol Sci. 1981;51:279-287.

134. Rossor M, Iversen L. Non-cholinergic neurotransmitter abnormalities in Alzheimer's disease. Br Med Bull. 1986;42:70-74.

135. Robertson D, Goldberg MR, Hollister AS, Wade D, Robertson RM. Clonidine raises blood pressure in severe idiopathic orthostatic hypotension. Am J Med. 1983;74:193-200.

136. Eason M, Liggett S. Subtype selective desensitization of alpha-2 adrenergic receptors. Different mechanisms control short and long term agonist-promoted desensitization of Alpha 2C10, Alpha 2C4, and alpha 2C2. J Biol Chem. 1992;267:225479-254873.

137. Daunt DA, Hurt C, Hein L, Kallio J, Feng F, Kobilka BK. Subtype specific intracellular trafficking of alpha -2 adrenergic receptors. $\mathrm{Mol}$ Pharmacol. 1997;51:711-720.

138. Zubenko G, Cohen B, Lipinski J, Jonas JM. Clonidine in the treatment of mania and mixed bipolar disorder. Am J Psychiatry. 1984;141:617-618.

139. Liebowitz M, Fyer A, McGarth P, et al. Clonidine treatment of panic disorder. Psychopharmacol Bull. 1981;17:122-123.

140. Nishikawa T, Tanaka M, Koga I, Uchida Y. Combined treatment of tardive dyskinesia with clonidine and neuroleptics: a follow up study of three cases for three years. Psychopharmacology. 1983;80:374-375.
141. Nishikawa T, Tanaka M, Tsuda A, Koga I, Uchida Y. Clonnidine therapy for tardive dyskinesia and related syndromes. Clin Neuropharmacol. 1984; 7:239-245.

142. Zubenko GS, Cohen BM, Lipinski JF Jr, Jonas JM. Use of clonidine in the treatment of akathisia. Psychiatry Res. 1984;13:253-259.

143. Adler LA, Angrist B, Peselow E, Reitano J, Rotrosen J. Clonidine in neuroleptic - induced akathisia. Am J Psychiatry. 1987;144: 235-236.

144. Svensson T, Bunney B, Aghajanian G. Inhibition of both noradrenergic and serotonergic neurons in brain by the a-adrenergic agonist clonidine. Brain Res. 1975;92(2):291-306.

145. Goldenberg G, Bharathan T, Shifrin I. Transdermal clonidine in patients with swallowing dysfunction. J Palliat Med. 2014;17(9): 1042-1044.

146. Panossian A, Wikman G, Wagner H. Plant adaptogens. III. Earlier and more recent concepts of their mode of action. Phytomedicine. 1999;6(4):287-300.

147. Selye H. Stress. Montreal: Acta Medical Publisher; 1950.

148. Samuelson G, Bohlin L. Drugs of Natural Origin. A Ttreatise of Pharmacology. 6th ed. Stokholm: Swedish Academy of Pharmaceutical Sciences; 2009.

149. Panossian A, Hamm R, Kadioglu O, Wikman G, Efferth T. Synergy and antagonism of active constituens of ADAPT -232 on transcriptional level of metabolic regulation of isolated neuroglial cells. Front Nerosci. 2013;7:Article16.

150. Von Zastrow M. Regulation of $G$ protein coupled receptors by phopshorilation and endocytosis. In: Davis K, Charney D, Coyle J, Nmeroff C, editors. Neuropsychopharmacology: The Fifth Generation of Progress. (Chap 5). Philadelphia: Lipppincott Williams \& Wilkins; 2002:59-70.
Research and Reports in Transdermal Drug Delivery

\section{Publish your work in this journal}

Research and Reports in Transdermal Drug Delivery is an international, peer-reviewed, open access online journal publishing original research, study protocols, reviews, editorials and commentaries on all aspects of transdermal drug delivery. Specific topics in the journal include: Laboratory and clinical development of drug delivery systems including preclinical, clinical studies and protocols; Rationale and basic science; Drug

\section{Dovepress}

delivery via gels, creams or patches; Use of chemical drug penetration enhancers Patient acceptability studies; and pharmacoeconomic and clinical outcome studies. The manuscript management system is completely online and includes a very quick and fair peer-review system, which is all easy to use. Visit http://www.dovepress.com/ testimonials.php to read real quotes from published authors. 